\title{
The Nutritional Value and Physiological Properties of Diets with Raw and Candida utilis-Fermented Lupin Seeds in Rats
}

\author{
Małgorzata Kasprowicz-Potocka ${ }^{1 *}$, Anita Zaworska ${ }^{1}$, Andrzej Frankiewicz, \\ Włodzimierz Nowak ${ }^{1}$ Piotr Gulewicz'2, Zenon Zduńczyk ${ }^{3}$ and Jerzy Juśkiewicz ${ }^{3}$ \\ ${ }^{1}$ Department of Animal Nutrition and Feed Management, Poznan University of Life Sciences, \\ Wołynska 33, PL-60-637 Poznan, Poland \\ ${ }^{2}$ Poznan Science and Technology Park, Adam Mickiewicz University Foundation, Rubiez 46, \\ PL-61-612 Poznan, Poland \\ ${ }^{3}$ Institute of Animal Reproduction and Food Research, Polish Academy of Sciences, Tuwima 10, \\ PL-10-747 Olsztyn, Poland \\ Received: November 6, 2014 \\ Accepted: March 25, 2015
}

\begin{abstract}
Summary
The growth and physiological responses of the rats to diet supplemented with raw and Candida utilis-fermented yellow and blue lupin seeds were determined. The diets containing soya bean meal, raw and fermented blue and yellow lupin were administered to eight rats in each diet group for four weeks. Yellow lupin seeds in the diets of rats improved significantly $(\mathrm{p}<0.05)$ feed intake, protein digestibility, body mass gain and protein efficiency ratio in comparison with blue lupin seeds. On the contrary, blue lupin seeds affected significantly $(\mathrm{p}<0.05)$ gastrointestinal fermentation processes in comparison with yellow lupin seeds. Fermentation of lupin seeds increased crude protein content and reduced phytate and oligosaccharide content. In the fermented products, a higher number of lactic acid bacteria and yeasts but reduced number of coliform bacteria was found. Fermentation by Candida utilis positively $(\mathrm{p}<0.05)$ affected protein digestibility of feed, body mass gain and protein efficiency ratio of rats, as well as the activity of some bacterial enzymes and cholesterol concentrations in the blood serum.
\end{abstract}

Key words: fermentation, lupin, Candida utilis, digestive tract, rats

\section{Introduction}

Functional foods have recently gained much attention because of their nutrient composition and beneficial impact on consumer health (1). One of the treatments used to increase health-promoting properties of the products is the fermentation of raw materials (2-4). Fermented products, in addition to their nutrient content (proteins, fibre, minerals and vitamins) usually include live, dried or lyophilized cells of lactic acid bacteria or yeast, which can work probiotically or prebiotically on digestive tract microflora (5-7). Fermentation is a natural and cheap method of changing the physical, chemical and functional parameters of food and feed $(8,9)$. Supplementation of fermented components to feed has a beneficial effect on growth performance and intestinal microflora regulation in pigs and rats (10-12). Yeast fermentation of starch components such as peas, beans or crops enriches products with high-value proteins of microbial origin, improves the digestibility of the protein and amino acid profile and reduces the concentration of antinutritional factors $(9,13)$, but the effect of lupin fermentation has not been determined so far.

Lupins are a protein-rich plant source for animals and people. The presence of antinutritive factors in lupin 
seeds has a negative effect on the availability and utilization of nutrients by monogastric organisms (14). Results of another study (15) indicate that raffinose family oligosaccharides (RFOs) more than alkaloids can reduce the utilization of nutrients of low-alkaloid lupin seeds. The bacterial conversion of carbohydrates, proteins and antinutritive compounds present in raw lupin seeds leads to the formation of a large number of substances that may have beneficial or adverse effects on human and animal health. RFOs are not hydrolyzed by native digestive enzymes of non-ruminant animals, but only by bacterial $\alpha$-galactosidase in the large intestine to gases, which can interfere with nutrient absorption (15) and cause flatulence and diarrhoea $(16,17)$. On the other hand, oligosaccharides and polysaccharides are recognized as potential substrates for fermentation by positive bacteria which can stimulate their proliferation and activity (4). It must also be mentioned here that in many countries, where lupin has already been accepted by consumers, there are reports about allergic reactions following consumption of lupin-containing products. Allergenic potential of lupin derives from its infiltration into organism through the respiratory system and after eating lupin-fortified products. The results suggest that lupin allergens are heat stable but their status after fermentation was not recognized (18). Lactofermentation of lupin seeds improved the gut health of rats as compared to raw seeds (4). Fermentation of $\mathrm{Lu}$ pinus angustifolius seeds using yeast increased the concentrations of proteins and essential amino acids, and significantly reduced the concentrations of oligosaccharides and phytates (19). Moreover, the products are characterized by acidic $\mathrm{pH}$ with prevalence of lactic and propionic acids, which is beneficial because of their positive impact on the gastrointestinal microflora (a natural acidifier). There are only a few studies concerning the nutritional value and physiological properties of fermented lupin seeds used in animal nutrition (4). Candida utilis was selected for this study on the basis of previously conducted experiments, which used different yeast strains for lupin seed fermentation, where it was recognized as the most efficient strain (data not published).

This study presents the effects of raw and Candida utilis-fermented yellow and blue lupin seeds in comparison with soya bean meal on the growth and conditions of intestinal ecosystems of rats and metabolic activity of their intestinal microflora, determined on the basis of activities of selected enzymes and concentrations of volatile products in caecum digesta.

\section{Materials and Methods}

\section{Microorganisms and fermentation media}

For the experiments and preparation of fermented products, seeds of Lupinus luteus (cv. Lord) and Lupinus angustifolius (cv. Graf) were selected. Seeds were obtained from the Plant Breeding Station Przebedowo (Przebedowo, Poland). Soya bean meal was obtained from the market.

For fermentation, a Candida utilis strain was acquired from the Pure Culture Collection of Industrial Microorganisms LOCK 105 at the Institute of Fermentation Tech- nology and Microbiology, Technical University of Lodz (Poland). Initially, yeast grew at $30^{\circ} \mathrm{C}$ for $48 \mathrm{~h}$ in sterilized tubes filled with an enriched YPD base (glucose $20 \mathrm{~g} / \mathrm{L}$, yeast extract $10 \mathrm{~g} / \mathrm{L}$, bacteriological peptone $20 \mathrm{~g} / \mathrm{L}$; all Oxoid, Hampshire, UK). Then, the content of five tubes was transplanted to the sterilized bottle filled with enriched YPD base, and incubated at $30^{\circ} \mathrm{C}$ for the next $48 \mathrm{~h}$. A mass of $2 \mathrm{~kg}$ of lupin meal was mixed with $8 \mathrm{~L}$ of distilled water in autoclaved plastic fermentation buckets and mixed vigorously. Mixtures were sterilized at $121{ }^{\circ} \mathrm{C}$ for $30 \mathrm{~min}$ in a Getinge autoclave (Getinge, Rastatt, Germany). After cooling, the resulting suspension was inoculated with yeast (10\% inoculum, by volume) and mixed. Fermentation was conducted for $72 \mathrm{~h}$ at $30^{\circ} \mathrm{C}$ under anaerobic conditions. Next, the yeast enzymes were deactivated for $30 \mathrm{~min}$ at $80^{\circ} \mathrm{C}$, and the material was dried at 55 ${ }^{\circ} \mathrm{C}$. Fermented yellow and blue lupin seed products were obtained.

\section{Animals and diets}

The experimental animals were used in compliance with European Guidelines for the Care and Use of Laboratory Animals next to the approval of the Ethical Committee for Animal Experimentation in Northeastern Poland. The experiment was performed on 40 male Wistar rats aged approx. 4 weeks. The experimental diets were administered for four weeks to eight rats per each group housed individually in Plexiglas cages. The administered diets had a similar content of proteins, fat, minerals and vitamins. Control diets contained $20.5 \%$ of soya bean meal, $70.3 \%$ of wheat, $5 \%$ of soya bean oil, $3 \%$ of AIN-93 mineral premix and $1 \%$ of AIN-93 vitamin premix (American Society for Nutrition, Bethesda, MD, USA) and 0.2 $\%$ of choline chloride, whereas in the experimental diets soya bean meal was replaced by raw or fermented blue and yellow lupin seeds (at 33.8, 27.0, 28.5 and $19.3 \%$, respectively) and wheat levels were 57.0, 63.8, 61.9 and 71.5 $\%$, respectively. The protein content in all the diets was about $18.5 \%$. Experimental diets and tap water were administered ad libitum. The animals were kept under standard conditions at a temperature of $21-22{ }^{\circ} \mathrm{C}$, relative air humidity of $50-70 \%$, with intensive room ventilation and a 12-hour light regimen. Individual body mass and food intake were recorded.

\section{Sample collection}

In the last week of the experiment, the rats were placed in the balance cages (Tecniplast Spa, Buguggiate, Italy) and faeces and urine were quantitatively collected to a plastic bag to calculate the protein digestibility coefficients and nitrogen balance of the diets. After four weeks of the experiment, the rats were anaesthetized using sodium pentobarbitone (14 $\mathrm{mg}$ per $\mathrm{kg}$ of body mass). Blood samples were collected from the caudal vena cava. Serum samples were prepared by centrifugation at $1500 \times g$ for 15 min at $4{ }^{\circ} \mathrm{C}$, and then stored at $-40^{\circ} \mathrm{C}$ for further analyses. After laparotomy, selected parts of the digestive tract (small intestine, caecum, colon) were removed and weighed. Directly after euthanasia (approx. $10 \mathrm{~min}$ ), ileal, caecal and colonic $\mathrm{pH}$ values were measured, tissue samples were collected to determine dry matter, ammonia and short-chain fatty acid contents, and the remaining material was 
frozen at $-70{ }^{\circ} \mathrm{C}$ for the determination of protein content and microbial enzyme activity. The ileal, caecal and colonic walls were flushed clean with ice-cold saline, blotted on filter paper, and weighed to determine tissue mass.

\section{Chemical and microbial analysis}

For chemical analysis, all the samples were ground to pass through a $0.5-\mathrm{mm}$ sieve. Dry matter, crude protein, ether extract, crude fibre, crude ash, acid detergent fibre and neutral detergent fibre were analyzed in duplicate in raw seeds, fermented products and digesta samples using methods 934.01, 976.05, 920.39, 978.10, 942.05 and 973.18 respectively, according to AOAC (20). Lupin alkaloids were extracted from flour by trichloroacetic acid and methylene chloride (Sigma-Aldrich, Munich, Germany). The determination of alkaloids was done using gas chromatography method (Shimadzu GC17A, Kyoto, Japan) with a capillary column (Phenomenex, Torrance, CA, USA). Raffinose family oligosaccharides (RFOs) were extracted and analyzed by high-resolution gas chromatography as described previously by Zalewski et al. (21). Phytate content was analyzed according to AOAC method 986.11 (20). The amino acid content was determined with an AAA-339 Mikrotechna amino acid analyzer (Prague, Czech Republic), using ninhydrin for post-column derivatization. Before analysis, the samples were hydrolyzed with $6 \mathrm{M} \mathrm{HCl}$ for $24 \mathrm{~h}$ at $110^{\circ} \mathrm{C}$ according to AOAC method $994.12(20)$.

Samples for bacteriological analysis were prepared by adding $27 \mathrm{~mL}$ of buffered peptone water (Oxoid) to $3 \mathrm{~g}$ of samples and homogenizing for $30 \mathrm{~s}$ in a laboratory stomacher. Microbial counts were determined using a decimal dilution series of homogenized samples. The total bacteria count and lactic acid bacteria count were determined by plate standard methods using plate count agar and MRS broth (Oxoid), respectively, after 72-hour incubation at $30^{\circ} \mathrm{C}$. The Salmonella count was determined using pre-supplemented dichloran Rose Bengal chloramphenicol (DRBC) and Salmonella Chromogen agar (Oxoid), after 18 and $24 \mathrm{~h}$ of incubation, respectively, at $37^{\circ} \mathrm{C}$. The yeast count was determined using pre-supplemented DRBC (Oxoid) after incubation at $25^{\circ} \mathrm{C}$ for $3-5$ days. Coliform bacteria were determined using Violet Red Bile lactose agar (Oxoid) after $24 \mathrm{~h}$ of incubation at $30^{\circ} \mathrm{C}$.

The caecal $\mathrm{pH}$ was measured using a microelectrode and a $\mathrm{pH} / \mathrm{Ion}$ meter (model 301, Hanna Instruments, Vila do Conde, Portugal). Ammonia was extracted and trapped in a boric acid solution, and it was analyzed by direct titration with sulphuric acid (POCh, Gliwice, Poland). Short-chain fatty acids in fresh caecal contents were determined by gas chromatography (Shimadzu GC-14A, Kyoto, Japan) with a $2.5 \mathrm{~mm} \times 2.6 \mathrm{~mm}$ glass column containing $10 \%$ SP-1200/1 \% $\mathrm{H}_{3} \mathrm{PO}_{4}$ on 80/100 Chromosorb WAW (Shimadzu Corp.); column temperature $110^{\circ} \mathrm{C}$, flame ionization detector (FID) temperature $180{ }^{\circ} \mathrm{C}$ and injector temperature $195{ }^{\circ} \mathrm{C}$. Aliquots of caecal digesta were mixed with $0.2 \mathrm{~mL}$ of formic acid (POCh), diluted with deionized water and centrifuged at $10000 \times g$ for $5 \mathrm{~min}$. Samples of the supernatant were subjected to gas chromatography analysis. Caecal short-chain fatty acid pools were calculated as the acid concentration per caecal digesta mass.
The activity of microbial enzymes ( $\alpha$ - and $\beta$-glucosidase, $\alpha$ - and $\beta$-galactosidase, $\beta$-glucuronidase and xylosidase) was measured on the basis of the rate of $p$-nitrophenol and $o$-nitrophenol release from nitrophenyl glucosides, and it was expressed in micromoles of the product formed per hour per gram of caecal digesta at $10000 \times g$ for $10 \mathrm{~min}$. Glucose, cholesterol, triacylglycerol and cholesterol concentrations in the serum were determined using Alpha Diagnostics (Warsaw, Poland) and Pointe Scientific (Warsaw, Poland) commercial kits.

\section{Statistical analysis}

Each group was compared with the control treatment using student's $t$-test and then the data (except the control group) were analyzed by two-way ANOVA with two main factors: lupin type (blue and yellow) and fermentation effect (untreated and fermented with Candida utilis plant material). If significance was observed $(p<0.05)$, Duncan's multiple range test was used to identify differences in the effect of individual diets. Calculations were made with STATISTICA v. 10.0 software (StatSoft Corporation, Kraków, Poland).

\section{Results}

\section{Chemical composition of raw and fermented lupin meal}

Seeds of yellow lupin contained more crude protein than raw blue lupin seeds (37.3 vs. $31.5 \%$, Table 1). Yellow lupin seeds were characterized by a higher mass fraction of true proteins and amino acids in dry matter than blue lupin seeds. The content of crude, acid and neutral detergent fibres was similar in the seeds of both lupin species. The total alkaloid level was twice as high in yellow lupin seeds. Mass fractions of phytate phosphorus and RFOs were also higher in yellow lupin seeds.

Fermentation by yeast culture increased the crude protein content for about 13.5 and $26 \%$ in comparison with raw seeds of blue and yellow lupin, respectively. On the other hand, the level of true protein, and especially the methionine mass fraction, was lower in the dry matter of fermented products than in raw seeds. The content of lysine, cystine and threonine in dry matter of fermented seeds was higher than in the raw material. Fermentation by Candida utilis partly reduced the crude fibre, acid detergent fibre and neutral detergent fibre content in comparison with unprocessed seeds. The level of alkaloids increased almost three times in fermented products and reached about $0.042 \%$ in fermented yellow lupin seeds. Phytate phosphorus mass fraction decreased the most (about 67 and $29 \%$ in blue and yellow lupin, respectively) after fermentation. Oligosaccharides of raffinose family disappeared after fermentation.

\section{Microbial status of raw and fermented lupin meal}

Fermentation effectively reduced the $\mathrm{pH}$ of lupin products from about 5.5 in raw seeds to about 4.0. The total count of bacteria, lactic acid bacteria and coliform bacteria counts were similar in both lupin species (Table 2). The yeast count was slightly higher in blue lupin seeds. 
Table 1. Chemical composition of raw and fermented lupin seeds

\begin{tabular}{|c|c|c|c|c|}
\hline & \multicolumn{4}{|c|}{$w / \%$} \\
\hline & \multicolumn{2}{|c|}{ Raw seeds } & \multicolumn{2}{|c|}{ Fermented seeds } \\
\hline & Blue lupin & Yellow lupin & Blue lupin & Yellow lupin \\
\hline Dry matter & $87.94 \pm 0.02$ & $88.6 \pm 0.22$ & $96.33 \pm 0.04$ & $94.99 \pm 0.13$ \\
\hline Crude protein & $31.5 \pm 0.6$ & $37.3 \pm 0.5$ & $35.7 \pm 0.2$ & $47.0 \pm 0.3$ \\
\hline True protein & $26.4 \pm 0.8$ & $29.6 \pm 1.0$ & $21.2 \pm 0.1$ & $28.1 \pm 0.6$ \\
\hline Lysine & $1.29 \pm 0.02$ & $1.65 \pm 0.01$ & $1.54 \pm 0.02$ & $2.02 \pm 0.01$ \\
\hline Methionine & $0.16 \pm 0.01$ & $0.20 \pm 0.02$ & $0.10 \pm 0.01$ & $0.17 \pm 0.01$ \\
\hline Cystine & $0.36 \pm 0.04$ & $0.71 \pm 0.02$ & $0.64 \pm 0.02$ & $0.90 \pm 0.01$ \\
\hline Threonine & $0.94 \pm 0.05$ & $1.08 \pm 0.03$ & $1.02 \pm 0.01$ & $1.24 \pm 0.03$ \\
\hline Crude ash & $3.4 \pm 0.1$ & $4.2 \pm 0.1$ & $3.5 \pm 0.1$ & $4.5 \pm 0.1$ \\
\hline Crude fibre & $15.2 \pm 0.4$ & $15.6 \pm 0.2$ & $14.3 \pm 0.6$ & $12.7 \pm 0.6$ \\
\hline Acid detergent fibre & $19.9 \pm 0.2$ & $18.7 \pm 0.9$ & $19.7 \pm 0.5$ & $16.1 \pm 0.4$ \\
\hline Neutral detergent fibre & $24.7 \pm 0.1$ & $24.5 \pm 1.0$ & $21.1 \pm 0.7$ & $18.9 \pm 1.3$ \\
\hline Total alkaloids & $0.007 \pm 0.001$ & $0.016 \pm 0.001$ & $0.021 \pm 0.003$ & $0.042 \pm 0.003$ \\
\hline Total RFOs & $6.6 \pm 0.2$ & $7.9 \pm 0.3$ & $0.0 \pm 0.0$ & $0.0 \pm 0.0$ \\
\hline Phytate phosphorus & $0.36 \pm 0.07$ & $0.59 \pm 0.03$ & $0.12 \pm 0.01$ & $0.42 \pm 0.09$ \\
\hline
\end{tabular}

The results are expressed as mean values \pm standard deviation (S.D.). RFOs=raffinose family oligosaccharides

Table 2. Microbial status of raw and fermented lupin seeds

\begin{tabular}{lccccc}
\hline & \multicolumn{2}{c}{ Raw seeds } & & \multicolumn{2}{c}{ Fermented seeds } \\
\cline { 2 - 3 } \cline { 5 - 6 } & Blue lupin & Yellow lupin & & Blue lupin & Yellow lupin \\
\hline $\mathrm{pH}$ & $5.5 \pm 0.1$ & $5.6 \pm 0.2$ & & $4.11 \pm 0.1$ & $3.98 \pm 0.1$ \\
\hline Total bacteria & $5.4 \cdot 10^{5} \pm 1.1 \cdot 10^{2}$ & $4.6 \cdot 10^{5} \pm 1.4 \cdot 10^{3}$ & & $2.5 \cdot 10^{6} \pm 1.4 \cdot 10^{3}$ & $8.4 \cdot 10^{5} \pm 1.1 \cdot 10^{3}$ \\
Lactic acid bacteria & $2.4 \cdot 10^{4} \pm 7.1 \cdot 10^{2}$ & $3.9 \cdot 10^{4} \pm 1.2 \cdot 10^{2}$ & & $4.8 \cdot 10^{6} \pm 3.1 \cdot 10^{3}$ & $7.0 \cdot 10^{5} \pm 1.1 \cdot 10^{3}$ \\
Yeast & $2.3 \cdot 10^{4} \pm 9.9 \cdot 10^{2}$ & $3.7 \cdot 10^{3} \pm 1.1 \cdot 10^{2}$ & & $4.0 \cdot 10^{6} \pm 1.1 \cdot 10^{4}$ & $3.4 \cdot 10^{6} \pm 2.1 \cdot 10^{3}$ \\
Coliform bacteria & $5.5 \cdot 10^{4} \pm 2.4 \cdot 10^{2}$ & $7.5 \cdot 10^{4} \pm 4.2 \cdot 10^{2}$ & & $1.5 \cdot 10^{3} \pm 1.4 \cdot 10^{2}$ & $1.5 \cdot 10^{4} \pm 9.1 \cdot 10^{2}$ \\
Salmonella sp. & $0.0 \pm 0.0$ & $0.0 \pm 0.0$ & & $0.0 \pm 0.0$ & $0.0 \pm 0.0$ \\
\hline
\end{tabular}

Salmonella was not detected in all the material. Fermented products were characterized by a higher content of total bacteria than unprocessed seeds. The fermentation process increased lactic acid bacteria (about $10^{1}$ to $10^{2}$ ) and yeast $\left(10^{2}\right.$ to $\left.10^{3}\right)$ number but reduced the number of coliform bacteria.

\section{Intake and utilization of diets with different protein sources}

The use of comparable high-protein components in the diets of the rats, in supplementation to wheat meal, soya bean oil and mineral and vitamin mixtures, diversified the diet intake and some parameters of nutrient utilization (Table 3). Higher feed intake was observed in the group fed fermented yellow lupin $(p=0.039)$ than in the control diet (soya bean meal). In this group, also a higher apparent protein digestibility $(p=0.001)$ and in the group fed fermented blue lupin a higher nitrogen balance $(p=0.031)$ were found, which did not result in a higher body mass gain of rats. Lower body mass gain in the rats fed blue lupin, yellow lupin and fermented blue lupin seeds $(p=0.001)$ and lower protein efficiency ratio in those fed blue lupin seeds were recorded than in the control. The results of two-way ANOVA showed that the inclusion of the blue lupin meal in the diets, compared to yellow lupin, reduced diet intake $(\mathrm{p}=0.043)$, apparent protein digestibility coefficient $(\mathrm{p}=0.004)$, final body mass $(\mathrm{p}=0.005)$, body mass gain $(p=0.002)$ and protein efficiency ratio $(p=0.035)$. The use of fermented lupin seeds increased the apparent protein digestibility $(\mathrm{p}=0.030)$, body mass gain $(p=0.028)$ and protein efficiency ratio $(p=0.005)$, compared to unprocessed seeds.

The applied dietary treatments did not affect the mass fraction and the $\mathrm{pH}$ of the small intestine, but changed some of the parameters of the caecum and colon of rats (Table 4). Compared to the group consuming soya bean meal, a higher mass fraction of tissue $(p=0.001)$ and digesta $(\mathrm{p}=0.001)$, and $\mathrm{pH}(\mathrm{p}=0.002)$ as well as a lower content of ammonia $(p=0.001)$ were detected in the caecum of rats fed blue lupin and fermented blue lupin seeds. A higher $\mathrm{pH}$ of the caecum was also found after the application of the other diets (yellow lupin and fermented yellow lupin). Compared to the soya bean meal diet, the use of all of the experimental diets resulted in increased 

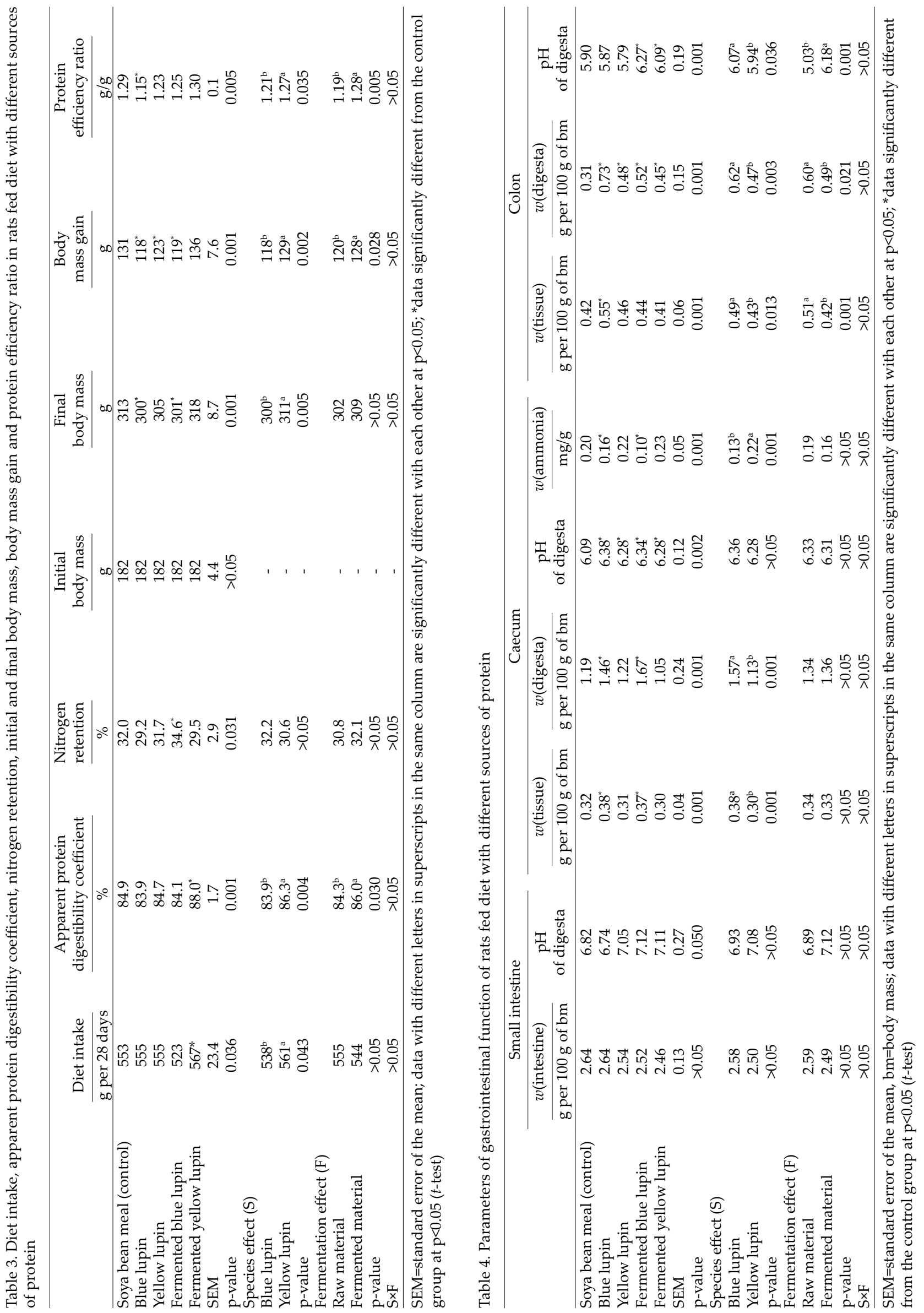
colon mass fraction $(\mathrm{p}=0.001)$, and the fermented blue lupin and fermented yellow lupin diets increased the $\mathrm{pH}$ of colon digesta $(\mathrm{p}=0.001)$, while the diet with the blue lupin increased the colon mass fraction $(\mathrm{p}=0.001)$. The results of two-way ANOVA showed that the addition of blue lupin seeds to the diet, compared to the yellow lupin, resulted in an increase in the caecal digesta (about $39 \%$ ) and the caecal tissue mass fraction by about $27 \%$ (both $p=0.001$ ) and the reduction of the ammonia content of the caecal digesta (about $69 \%$; $p=0.001$ ). Seeds of blue lupin in the diet also increased the mass fraction of the colon digesta and the colon tissue ( $\mathrm{p}=0.003$ and $\mathrm{p}=0.013$, respectively), and the $\mathrm{pH}$ of colon digesta, in comparison with yellow lupin in the diet. Yeast fermentation of lupin seed meal caused a decrease in the mass fraction of colon digesta and digesta $\mathrm{pH}(\mathrm{p}=0.021$ and $\mathrm{p}=0.001$, respectively), and reduction in colon tissue mass fraction $(\mathrm{p}=0.001)$.

\section{Microbial enzyme activity and short-chain fatty acids in the caecal digesta}

The applied dietary treatments did not affect the activity of microbial $\alpha$ - and $\beta$-glucosidase in the caecal digesta of rats (Table 5). The microbial activity of $\alpha$-galactosidase was reduced in the groups fed fermented blue and yellow lupin (about 31 and $43 \%$, respectively) ( $p=$ $0.001)$, but $\beta$-galactosidase activity was lower $(\mathrm{p}=0.001)$ in the group fed fermented yellow lupin only, in comparison with the control group. The activity of $\beta$-glucuronidase was lower in the rats fed blue lupin ( $p=0.023)$ than in the control. Xylosidase activity was higher in the group consuming fermented yellow lupin in comparison with the control $(\mathrm{p}=0.001)$.

The results of two-way ANOVA showed that the content of blue lupin seeds in the diet resulted in lower xylosidase activity in caecal digesta $(\mathrm{p}=0.002)$ than the diet with yellow lupin. Fermentation of lupin seeds decreased the activity of $\alpha$ - and $\beta$-galactosidase (both $\mathrm{p}=0.001$ ) about 64-68 \%, but increased the activity of $\beta$-glucuronidase $(\mathrm{p}=0.017)$ and xylosidase $(\mathrm{p}=0.005)$ about $35 \%$ in comparison with unprocessed lupin seeds.

The content of acetate in the caecum of animals from the groups consuming blue lupin and fermented blue lupin seeds was lower $(\mathrm{p}=0.001)$ than in the group consuming soya bean meal (Table 6). The content of propionate in the digesta of the rats fed yellow lupin, fermented blue lupin and fermented yellow lupin seeds was significantly lower than in the control group ( $p=0.014)$. In the control group, the valeriate content in the caecum was significantly higher $(p=0.002)$ than in other groups. The content of isobutyrate, butyrate and isovaleriate was similar in all the groups $(p>0.05)$. The propionate pool was lower in the groups fed yellow lupin and fermented yellow lupin $(\mathrm{p}=0.002)$, and butyrate and the total short-chain fatty acid pool in that fed fermented blue lupin (both $\mathrm{p}=0.001$ ) than in the control group. The mass fraction of acetate was lower and of butyrate was higher in the groups consuming blue lupin and fermented blue lupin (both $\mathrm{p}=0.001$ ), compared to the control. The propionate mass fraction in the total short-chain fatty acid profile was lower $(\mathrm{p}=0.016)$ in the groups fed blue or yellow lupin than in the control group.

The results of two-way ANOVA showed that the addition of blue lupin seeds to the diet resulted in a lowered acetate but higher butyrate fraction in digesta, compared to yellow lupin seeds $(\mathrm{p}=0.001$ and $\mathrm{p}=0.028$, respectively). Moreover, diets containing blue lupin seeds resulted in a higher propionate, butyrate and total short-chain fatty acid pool (for all, $p=0.001$ ) than yellow lupin diets. Blue lupin seeds in diets also increased the propionate and butyrate mass fractions $(p=0.016$ and $p=0.001$,

Table 5. Microbial enzyme activity in the caecal digesta of rats

\begin{tabular}{|c|c|c|c|c|c|c|}
\hline & \multicolumn{6}{|c|}{ Enzyme activity/(IU per g of digesta) } \\
\hline & $\alpha$-glucosidase & $\beta$-glucosidase & $\alpha$-galactosidase & $\beta$-galactosidase & $\beta$-glucuronidase & Xylosidase \\
\hline Soya bean meal (control) & 26.8 & 29.0 & 99.0 & 144 & 73.0 & 12.2 \\
\hline Blue lupin & 29.2 & 27.4 & 101 & 168 & $40.5^{*}$ & 10.3 \\
\hline Yellow lupin & 27.4 & 25.9 & 103 & 166 & 51.3 & 14.7 \\
\hline Fermented blue lupin & 30.0 & 30.7 & $68.0^{*}$ & 106 & 61.0 & 14.2 \\
\hline Fermented yellow lupin & 32.1 & 33.7 & $56.4^{*}$ & $93.3^{*}$ & 66.3 & $19.2^{*}$ \\
\hline SEM & 4.3 & 5.6 & 20.9 & 39.8 & 18.0 & 3.5 \\
\hline $\mathrm{p}$-value & $>0.05$ & $>0.05$ & 0.001 & 0.001 & 0.023 & 0.001 \\
\hline \multicolumn{7}{|l|}{ Species effect (S) } \\
\hline Blue lupin & 29.6 & 29.1 & 84.5 & 137.4 & 50.7 & $12.3^{\mathrm{b}}$ \\
\hline Yellow lupin & 29.8 & 29.8 & 79.8 & 129.7 & 58.8 & $16.9^{\mathrm{a}}$ \\
\hline p-value & $>0.05$ & $>0.05$ & $>0.05$ & $>0.05$ & $>0.05$ & 0.002 \\
\hline \multicolumn{7}{|l|}{ Fermentation effect $(F)$} \\
\hline Raw material & 28.3 & 26.7 & $102.1^{\mathrm{a}}$ & $167.3^{\mathrm{a}}$ & $45.9^{\mathrm{b}}$ & $12.5^{\mathrm{b}}$ \\
\hline Fermented material & 31.1 & 32.2 & $62.2^{\mathrm{b}}$ & $99.8^{\mathrm{b}}$ & $63.7^{\mathrm{a}}$ & $16.7^{\mathrm{a}}$ \\
\hline p-value & $>0.05$ & $>0.05$ & 0.001 & 0.001 & 0.017 & 0.005 \\
\hline$S \times F$ & $>0.05$ & $>0.05$ & $>0.05$ & $>0.05$ & $>0.05$ & $>0.05$ \\
\hline
\end{tabular}

SEM=standard error of the mean; data with different letters in superscripts in the same column are significantly different with each other at $\mathrm{p}<0.05$; ${ }^{*}$ data significantly different from the control group at $\mathrm{p}<0.05$ ( $t$-test) 
Table 6. Content of short-chain fatty acids (SCFA), their pool and profile in the caecal digesta of rats

\begin{tabular}{|c|c|c|c|c|c|c|c|}
\hline & \multicolumn{7}{|c|}{$b$ (SCFA) $/(\mu \mathrm{mol} / \mathrm{g})$} \\
\hline & acetate & propionate & isobutyrate & butyrate & isovaleriate & valeriate & Total SCFA \\
\hline Soya bean meal (control) & 122 & 22.2 & 1.29 & 68.6 & 1.29 & 5.41 & 220 \\
\hline Blue lupin & $96.6^{*}$ & 19.7 & 1.54 & 80.0 & 0.78 & $2.46^{*}$ & 201 \\
\hline Yellow lupin & 113 & $15.2^{*}$ & 1.80 & 66.1 & 1.15 & $2.57^{*}$ & 200 \\
\hline Fermented blue lupin & $90.4^{*}$ & $17.4^{*}$ & 1.19 & 81.1 & 1.19 & $1.89^{*}$ & 193 \\
\hline Fermented yellow lupin & 115.5 & $16.9^{*}$ & 1.13 & 70.6 & 0.93 & $2.47^{*}$ & 208 \\
\hline SEM & 15.8 & 3.5 & 0.6 & 11.3 & 0.4 & 1.2 & 23.4 \\
\hline $\mathrm{p}$-value & 0.001 & 0.014 & $>0.05$ & $>0.05$ & $>0.05$ & 0.002 & $>0.05$ \\
\hline \multicolumn{8}{|l|}{ Species effect (S) } \\
\hline Blue lupin & $93.4^{\mathrm{b}}$ & 18.6 & 1.36 & $80.6^{\mathrm{a}}$ & 0.98 & 2.18 & 197 \\
\hline Yellow lupin & $114.4^{\mathrm{a}}$ & 16.0 & 1.46 & $68.4^{\mathrm{b}}$ & 1.04 & 2.52 & 204 \\
\hline $\mathrm{p}$-value & 0.001 & $>0.05$ & $>0.05$ & 0.028 & $>0.05$ & $>0.05$ & $>0.05$ \\
\hline \multicolumn{8}{|l|}{ Fermentation effect $(F)$} \\
\hline Raw material & 104.9 & 17.4 & 1.67 & 73.1 & 0.96 & 2.52 & 201 \\
\hline Fermented material & 102.9 & 17.2 & 1.16 & 75.9 & 1.06 & 2.18 & 201 \\
\hline p-value & $>0.05$ & $>0.05$ & $>0.05$ & $>0.05$ & $>0.05$ & $>0.05$ & $>0.05$ \\
\hline \multirow[t]{3}{*}{$\mathrm{S} \times \mathrm{F}$} & $>0.05$ & $>0.05$ & $>0.05$ & $>0.05$ & $>0.05$ & $>0.05$ & $>0.05$ \\
\hline & \multicolumn{4}{|c|}{$b(\mathrm{SCFA}$ pool $) /(\mu \mathrm{mol} / 100 \mathrm{~g})$} & \multicolumn{3}{|c|}{$w(\mathrm{SCFA}) / \%$} \\
\hline & acetate & propionate & butyrate & Total SCFA & acetate & propionate & butyrate \\
\hline Soya bean meal (control) & 144 & 26.4 & 81.5 & 262 & 55.0 & 10.0 & 31.3 \\
\hline Blue lupin & 140 & 28.8 & 118 & 294 & $47.9^{*}$ & 9.92 & $39.8^{*}$ \\
\hline Yellow lupin & 139 & $18.5^{*}$ & 80.1 & 243 & 57.0 & $7.53^{*}$ & 32.7 \\
\hline Fermented blue lupin & 151 & 29.3 & $135^{*}$ & $322^{*}$ & $47.0^{*}$ & 8.98 & $41.8^{*}$ \\
\hline Fermented yellow lupin & 121 & $17.7^{*}$ & 74 & 218 & 55.8 & 8.21 & 33.8 \\
\hline SEM & 21.1 & 6.1 & 26.7 & 49.1 & 4.7 & 1.4 & 4.7 \\
\hline p-value & 0.274 & 0.002 & 0.001 & 0.003 & 0.001 & 0.016 & 0.001 \\
\hline \multicolumn{8}{|l|}{ Species effect (S) } \\
\hline Blue lupin & 146 & $29.1^{\mathrm{a}}$ & $126^{\mathrm{a}}$ & $307^{\mathrm{a}}$ & $47.4^{\mathrm{b}}$ & $9.45^{\mathrm{a}}$ & $40.8^{\mathrm{a}}$ \\
\hline Yellow lupin & 129 & $18.1^{\mathrm{b}}$ & $77^{\mathrm{b}}$ & $230^{\mathrm{b}}$ & $56.4^{\mathrm{a}}$ & $7.87^{\mathrm{b}}$ & $33.2^{\mathrm{b}}$ \\
\hline p-value & $>0.05$ & 0.001 & 0.001 & 0.001 & 0.001 & 0.016 & 0.001 \\
\hline \multicolumn{8}{|l|}{ Fermentation effect $(F)$} \\
\hline Raw material & 139 & 23.6 & 98 & 268 & 52.5 & 8.73 & 36.2 \\
\hline Fermented material & 136 & 23.5 & 104 & 270 & 51.4 & 8.59 & 37.8 \\
\hline p-value & $>0.05$ & $>0.05$ & $>0.05$ & $>0.05$ & $>0.05$ & $>0.05$ & $>0.05$ \\
\hline $\mathrm{S} \times \mathrm{F}$ & $>0.05$ & $>0.05$ & $>0.05$ & $>0.05$ & $>0.05$ & $>0.05$ & $>0.05$ \\
\hline
\end{tabular}

SEM=standard error of the mean; data with different letters in superscripts in the same column are significantly different with each other at $\mathrm{p}<0.05 ;{ }^{*}$ data significantly different from the control group at $\mathrm{p}<0.05$ ( $t$-test)

respectively) but reduced the acetate mass fraction $(\mathrm{p}=$ 0.001 ), compared to diets based on yellow lupin seeds. No effect of the fermentation process on the short-chain fatty acid content, their pool or profile was found $(p>0.05)$.

\section{Blood parameters}

There were no differences in the concentration of serum glucose $(p=0.130)$ among the groups (Table 7$)$. The content of triacylglycerols in blood serum of rats in all the experimental groups was significantly lower $(p=0.001)$ than in the group consuming soya bean meal. The blood of rats fed the diet containing blue lupin was characterized by the lower level of the total cholesterol and high-density lipoprotein cholesterol (HDL) than the control group, but the contribution of HDL cholesterol to the total cholesterol in the blood of rats of all the groups was similar.

Two-way ANOVA showed that blue lupin in the diets decreased the total cholesterol $(\mathrm{p}=0.031)$ and HDL cholesterol $(\mathrm{p}=0.017)$ in the blood plasma of rats, compared to diets based on yellow lupin seeds. Fermentation increased the total cholesterol $(p=0.009)$ and HDL cholesterol $(p=$ 0.025 ) in the blood plasma of rats, compared to raw seeds.

\section{Discussion}

In the present study, yellow lupin seeds are characterized by a higher content of crude and true proteins, as well as essential amino acid content than blue lupin seeds. Yellow lupin seeds also contained more antinutritional compounds. These results are generally consistent with those obtained in studies by Kim et al. (12), Jezierny et al. (14) and Chilomer et al. (22). Kim et al. (12) also found more antinutritional substances in the seeds of yellow than of blue lupin as opposed to Sobotka et al. (17). It is commonly known that the chemical composition of lupin seeds is strongly related to the variety and soil properties and, especially, environmental conditions during seed germination and maturation (23).

Fermentation increased the protein content and improved the amino acid profile of seeds. The mass fraction of methionine was lower but of cystine higher in the fermented material. A similar increase in the protein content after fermentation was observed by other authors $(9,13)$. During fermentation, yeast uses the available sources of nitrogen such as free amino acids, dipeptides, proteins, ammonium ions and urea for growth, which results in an 
Table 7. Biochemical indices of blood plasma of rats

\begin{tabular}{|c|c|c|c|c|c|}
\hline & $\frac{c \text { (glucose) }}{\mathrm{mmol} / \mathrm{L}}$ & $\frac{c \text { (triacylglycerols })}{\mathrm{mmol} / \mathrm{L}}$ & $\frac{c \text { (total cholesterol })}{\mathrm{mmol} / \mathrm{L}}$ & $\frac{c(\text { HDL cholesterol })}{\mathrm{mmol} / \mathrm{L}}$ & $\frac{w(\mathrm{HDL})^{* *}}{\%}$ \\
\hline Soya bean meal (control) & 13.0 & 2.20 & 1.84 & 1.18 & 64.3 \\
\hline Blue lupin & 13.2 & $1.76^{*}$ & $1.46^{*}$ & $0.93^{*}$ & 64.1 \\
\hline Yellow lupin & 13.0 & $1.37^{*}$ & 1.68 & 1.12 & 66.2 \\
\hline Fermented blue lupin & 11.4 & $1.53^{*}$ & 1.72 & 1.11 & 64.0 \\
\hline Fermented yellow lupin & 13.0 & $1.73^{*}$ & 1.88 & 1.25 & 66.5 \\
\hline SEM & 1.19 & 0.39 & 0.23 & 0.17 & 3.80 \\
\hline $\mathrm{p}$-value & 0.130 & 0.003 & 0.029 & 0.036 & 0.690 \\
\hline \multicolumn{6}{|l|}{ Species effect (S) } \\
\hline Blue lupin & 12.3 & 1.65 & $1.60^{\mathrm{b}}$ & $1.02^{\mathrm{b}}$ & 64.0 \\
\hline Yellow lupin & 12.9 & 1.55 & $1.78^{\mathrm{a}}$ & $1.18^{\mathrm{a}}$ & 66.4 \\
\hline p-value & $>0.05$ & $>0.05$ & 0.031 & 0.017 & $>0.05$ \\
\hline \multicolumn{6}{|l|}{ Fermentation effect $(F)$} \\
\hline Raw material & 13.1 & 1.56 & $1.57^{\mathrm{b}}$ & $1.02^{\mathrm{b}}$ & 65.1 \\
\hline Fermented material & 12.2 & 1.63 & $1.80^{\mathrm{a}}$ & $1.18^{\mathrm{a}}$ & 65.2 \\
\hline $\mathrm{p}$-value & $>0.05$ & $>0.05$ & 0.009 & 0.025 & $>0.05$ \\
\hline$S \times F$ & $>0.05$ & $>0.05$ & $>0.05$ & $>0.05$ & $>0.05$ \\
\hline
\end{tabular}

SEM=standard error of the mean; data with different letters in superscripts in the same column are significantly different with each other at $\mathrm{p}<0.05 ;{ }^{*}$ data significantly different from the control group at $\mathrm{p}<0.05$ ( $t$-test); *"high density lipoprotein (HDL) fraction in total cholesterol

intensive increase of biomass production (24). Khattab et al. (9) and Yabaya et al. (13) found an increase in the concentration of essential amino acids, including methionine, after fermentation of legume seeds, but in the present research the methionine content was reduced in both fermented products. This difference could be explained by the specificity of plant material and yeast used in the experiments.

In the fermented seeds, reduced content of crude fibre, acid detergent fibre and neutral detergent fibre as well as oligosaccharides and phytates were found. A similar effect of fermentation on carbohydrate structure was found by Canibe et al. (25). Structural carbohydrates are quite resistant to direct yeast digestion, but cellulose, hemicellulose and pectin can be metabolized by some non-yeast enzymes (24). Raffinose family oligosaccharides (RFOs) were completely removed during fermentation. These results are consistent with the results of Vidal-Valverde et al. (26), who found no RFOs in lentil seeds after natural fermentation. Khattab and Arntfield (27) found about $70 \%$ reduction of RFOs in different legume seeds after $24 \mathrm{~h}$ of fermentation by Saccharomyces cerevisiae. During fermentation, yeast produces different types of hydrolases, which degrade the oligosaccharides into simple sugars $(28,29)$. Candida utilis also reduced phytate phosphorus mass fraction by about $67 \%$ in blue and by $29 \%$ in yellow lupin. Yeasts have the ability to hydrolyze phytic acid into inositol and phosphoric acid (30). This phenomenon was confirmed by other authors. Khattab and Arntfield (27) found a reduction of phytate after $S$. cerevisiae fermentation of different legume seeds by about $30-35 \%$, and Egounlety and Aworth (28) a 30 to $60 \%$ reduction of phytate after fermentation by Rhizopus oligosporus. Among the antinutritional substances, only the lupin alkaloid content increased in fermented products in comparison with raw seeds. This was probably the result of the increase of the mass fraction of alkaloids in dry matter, reduced by a loss of degraded oligo- and polysaccharides. In previous studies, it was found that lupin alkaloids were resistant to Saccharomyces cerevisiae fermentation (19).

Fermentation by Candida utilis reduced the $\mathrm{pH}$ value, which was accompanied by an increase in the number of yeasts and lactobacilli. The number of Enterobactericeae decreased after fermentation. Similar results were found by Yabaya et al. (13), who observed a $\mathrm{pH}$ reduction from 5.6 to 5.1, and a significant increase in the number of yeasts during the fermentation of soya cake by $S$. cerevisiae for $24 \mathrm{~h}$. Mbata et al. (31) found that the addition of bambara groundnut to fermented maize flour reduced the $\mathrm{pH}$ and increased the number of yeasts and Lactobacillus spp. Canibe et al. (25) showed a similar increase in the number of yeasts and lactic acid bacteria and significant reduction in the number of Enterobacteriaceae in a study on fermenting grains. The $\mathrm{pH}$ reduction is due to the activity of microorganisms which degrade carbohydrates into organic acids $(19,32,33)$. The acidic conditions particularly promote the development of lactic acid bacteria and yeasts which can tolerate low $\mathrm{pH}$. Enterobacteriaceae, especially coliform bacteria, are acid intolerant, so their population is reduced (31).

The use of lupin components as a replacement for soya bean meal did not have a negative effect on the diet intake, digestibility and nitrogen retention, but it reduced the growth of rats. This is consistent with the results obtained by Sobotka et al. (17), who also found that the replacement of casein with blue and yellow lupin seeds in the diets did not reduce the feed intake but limited the 
growth rate of rats. It is probably the result of a better amino acid profile and lower content of antinutritional substances in the soya bean meal diet than in lupin-containing diets. On the other hand, in this research, the dietary intake, apparent protein digestibility, body mass gain and protein efficiency ratio of rats that were administered yellow lupin products in the diet was significantly higher than of those administered blue lupin. Sobotka et al. (17) did not find differences in the feed intake and body mass gain of rats that were administered diets containing yellow or blue lupin seeds. This implies that the diet intake and mass gain of animals depend on the content of some antinutritional substances in the diets, which was also confirmed by a comparison of the effects of feed containing raw and fermented lupin seeds. Fermented products contained low phytate and oligosaccharide levels but had higher alkaloid content. The use of fermented products increased the apparent protein digestibility, body mass gain and protein efficiency ratio in rats in comparison with raw seeds. These results are consistent with those obtained in studies by Bartkiene et al. (4) of yellow and white lupin seeds fermented with Pediococcus acidilactici. Previous studies on protein digestibility of legumes have shown interactions between antinutritional compounds (RFOs, phytates) and the protein and carbohydrate structure, forming complexes less susceptible to enzymes. Enzymes produced by yeast do not degrade complex carbohydrates; however, the acidic conditions $(\mathrm{pH}=4.0)$ and fermentation time (3 days) can accelerate the degradation of complex components by enzymes from the fermentation medium (7). The results suggest that lower digestibility and utilization of lupin diets is due to the presence of RFOs rather than alkaloids, which is consistent with the results obtained by Zduńczyk et al. (15), who show that oligosaccharides may reduce the intestinal absorption, thus decreasing protein digestibility and growth efficiency more than alkaloids. According to Seve et al. (16), the removal of $\alpha$-galactosides from soya flour had a small but beneficial influence on digestibility of nutrients and nitrogen utilization from piglet diets.

Experimental diets did not affect the small intestine parameters, but impacted the caecum and colon environment. In the digestive tract of animals fed blue lupin (raw or fermented) diets, a higher caecal tissue and digesta mass fractions and reduced ammonia mass fraction, and a higher colon tissue mass fraction were observed than in the control group. All diets containing lupin increased colon digesta mass fraction as compared to the soya bean meal diet. This is in accordance with the work of Bartkiene et al. (4), who used raw or fermented yellow and white lupin seeds in the diets of rats. Diets containing lupins significantly increased the mass fractions of caecal tissue and colon digesta in comparison with soya bean meal. This was also confirmed by Sobotka et al. (17) in rat diets which contained yellow and blue lupin cultivars in comparison with casein diet, and by Stanek and Bogusz (34) for diets with yellow lupin seeds. Zduńczyk et al. (15) found that the amount of toxic ammonia produced during the bacterial degradation of proteins tends to decrease in rats fed lupin seeds.

Higher caecal and colon tissue mass fractions, digesta mass fraction and also higher $\mathrm{pH}$ of colon digesta were found in animals offered blue lupin than yellow lupin diets.
This indicates that blue lupin seeds are more effectively fermented by ileal microflora. The same tendency in the caecum was found by Sobotka et al. (17). The increase in the caecal wall mass fraction could be due to the presence of short-chain fatty acid, produced during the bacterial degradation of carbohydrates from lupin seeds, which is consistent with a higher total short-chain fatty acid pool in digesta of rats fed blue lupin diet. The increase in the caecal digesta mass fraction could result from a greater bacterial count in the caecum (35). Sobotka et al. (17) found that diets based on blue lupin seeds increased the acidity of caecal digesta more than yellow lupin, but Bartkiene et al. (4) found no impact of lupin cultivar on the $\mathrm{pH}$ of the colon and caecum.

Fermentation had a significant effect only on the colon parameters. The use of fermented seeds in the diets reduced the colon tissue and digesta mass fractions in comparison with raw seeds. It indicated poorer microbial fermentation in this part of the ileum, which is probably the result of the lack of RFOs in the fermented products. Fermentation of lupin seeds did not lower the $\mathrm{pH}$ of digesta from the small intestine, caecum or colon. Bartkiene et al. (4) found a similar tendency in the $\mathrm{pH}$ value, digesta mass and ammonia production when the seeds of yellow and white lupin were fermented by Pediococcus acidilactici. Higher acidity levels could promote the development of beneficial microflora (Bifidobacterium or Lactobacillus) and prevent the growth of harmful bacteria (31).

In a digestive tract some microorganisms, especially the Enterobacteriaceae family, can produce hydrolytic enzymes which transform precarcinogens into active carcinogens. The activity of these enzymes ( $\alpha$ - and $\beta$-galactosidase, $\alpha$ - and $\beta$-glucosidase, $\beta$-glucuronidase, xylosidase) is often used as an indicator of the effect of additives on the intestinal microflora. In comparison with soya bean meal the activity of $\alpha$-galactosidase was reduced by fermented blue and yellow lupin diet, of $\beta$-galactosidase by fermented blue lupin and of $\beta$-glucuronidase by the blue lupin diet. Only xylosidase activity increased when using the fermented yellow lupin diet in comparison with soya bean meal. Moreover, the inclusion of blue lupin seeds in the diets of rats reduced the activity of xylosidase in comparison with yellow lupin seeds. Fermented products in the diets reduced significantly $\alpha$ - and $\beta$-galactosidase, but increased $\beta$-glucuronidase and xylosidase activities in comparison with raw seeds. This is consistent with research by Bartkiene et al. (4), who found the same tendency comparing diets containing raw blue lupin seeds and soya bean meal. On the contrary, Sobotka et al. (17) found that the use of diets with blue and yellow lupin seeds significantly increased $\alpha$ - and $\beta$-galactosidase and $\beta$-glucosidase activity in digesta of rats. Similarly, no impact of the lupin seed variety in the diet on $\alpha$-glucosidase and $\beta$-glucuronidase was observed. Comparing raw and lactofermented yellow lupin seeds, Bartkiene et al. (4) found a tendency which is similar to the one observed for $\alpha$-, $\beta$-glucosidase and $\alpha$-galactosidase. The activity of $\beta$-galactosidase and $\beta$-glucuronidase was higher in fermented seeds than in the raw material. The $\alpha$ - and $\beta$-glucosidase are involved in the degradation of structural carbohydrates (cellulose, hemicellulose) in the caecum and what is important is that they break down oligosaccharides to simple sugars by cleaving the glycosidic bonds (36). This can explain the significantly lower activity of these en- 
zymes in diets with fermented lupin seeds, which are characterized by a lower RFO content. On the other hand, an increase in the enzymatic activity in the caecal digesta can also indicate a rapid growth of beneficial bacteria in the caecum.

The rate of carbohydrate hydrolysis in the caecum is the result of short-chain fatty acid production. The total amount of short-chain fatty acids in the caecal digesta of control animals reached $220 \mu \mathrm{mol} / \mathrm{g}$, and it was similar to that noted in rats fed raw and fermented blue and yellow lupin seeds (193-208 $\mu \mathrm{mol} / \mathrm{g})$. In the caecal digesta of animals from all the groups offered lupin seeds (raw or fermented), reduced content of acetate, propionate and valeriate were found. The level of total short-chain fatty acids in the present work was higher than in the similar research provided by Bartkiene et al. (4), Juśkiewicz et al. (35) and Sobotka et al. (17). Juśkiewicz et al. (35) also found no differences in total short-chain fatty acid production in digesta between rats fed soya bean meal diet and raw or lactofermented seeds of yellow or white lupin, and reduction of acetic, propionic and valeric acid content. Sobotka et al. (17) showed that short-chain fatty acid production in caecal digesta of rats was similar when consuming diet containing blue lupin seeds but higher when consuming diet with yellow lupin seeds than in casein-based diet.

The lupin species did not affect the total short-chain fatty acid content, but in digesta of rats offered yellow lupin seeds, a significantly higher acetate and lower butyrate content was found. Sobotka et al. (17) showed that the production of short-chain fatty acids in rats offered a diet containing yellow lupin seeds was significantly higher than in the rats fed blue lupin, because of the differences in $\alpha$-galactoside content between the two cultivars. According to Bartkiene et al. (4), there were no differences in the short-chain fatty acid content of caecal digesta of rats offered raw yellow or white lupin seeds in the diets.

There were no differences in the short-chain fatty acid composition between groups as a consequence of fermentation, which was generally consistent with the results of Bartkiene et al. (4). Klewicka et al. (2) found that the concentration of propionic, butyric and valeric acids in the caecal digesta of rats was higher (than in the casein-based diet) when they were fed a diet containing fermented beetroot juice. It is worth noting that actual products were offered in a dry form, as opposed to Klewicka et al. (2) and Bartkiene et al. (4). This means that the activity of yeasts and bacteria present in the fermented mass could be partly inhibited (enzyme deactivation) and biomass could be used as a protein source in the initial segments of the digestive tract, which eliminated their expected probiotic effect in the distal part of the digestive tract of rats. Champ et al. (37) proved that short-chain fatty acid production originated in the ingestion of lupin meal (in comparison with isolated fibres) and that $50 \%$ of short-chain fatty acids appears to be derived from non-starch polysaccharides, and $50 \%$ from the $\alpha$-galactosides, which are not present in the fermented seeds.

Some researchers have suggested that the calculated short-chain fatty acid pool produced in the caecum provides more precise information on the effect of the applied preparations on the intensity of the fermentation in the gastrointestinal tract. The propionate pool was lower in diets with raw and fermented yellow lupin seeds but the butyrate and total short-chain fatty acid pools were higher in the diet containing fermented blue lupin than in the soya bean meal diet. In blue lupin diets significantly higher pools of propionate, butyrate and the total short-chain fatty acids were found than in yellow lupin seeds.

Generally, in digesta of rats, lower amounts of acetate and propionate but a higher content of butyrate were found than in rats fed soya bean meal. In the profile of short-chain fatty acids in digesta of animals offered blue lupin a lower level of acetate but higher levels of propionate and butyrate were detected than in diets containing yellow lupin. The profile of short-chain fatty acids in actual results was different from those presented by Bartkiene et al. (4), because of a lower propionate and a higher butyrate amount, probably because of different diet formulations.

Acetic acid is the major by-product of Bifidobacterium fermentation, which modifies the caecal ecosystem (36). Sobotka et al. (17) found that the propionic acid content in caecal digesta was dependent on oligosaccharide concentrations in diets, which is in opposition to our observations. Propionic acid is almost entirely metabolized in the liver, and it is capable of inhibiting hepatic cholesterol synthesis from acetic acid (38). The level of butyric acid increased after the administration of diets containing blue lupin seeds. Butyric acid is an important source of energy for epithelial cells and it regulates cell growth and differentiation. In our study, similarly to Sobotka et al. (17), an increase in butyric acid content was accompanied by an increase in the cecal wall mass fraction in rats offered blue lupin diets.

The replacement of soya bean meal with lupin seeds in the diets of rats decreased triacylglycerol concentrations in blood plasma. In animals fed a diet containing raw blue lupin seeds, a significant reduction in the concentration of total cholesterol and HDL cholesterol was found in comparison with the soya bean meal and yellow lupin diet. Fermentation significantly increased the total cholesterol and HDL cholesterol in blood plasma of rats. The results obtained are consistent with the results of other studies $(39,40)$. Spielmann et al. (41) found that a protein isolated from L. albus is strongly hypotriglyceridemic in rats, which is in part due to downregulation of SREBP$-1 \mathrm{c}$ in the liver, which, in turn, leads to a reduction in hepatic fatty acid synthesis. Osman et al. (42) suggest that the hypocholesterolemic effect of lupin seed supplements might be due to their abilities to lower the plasma cholesterol level as well as to slow down the lipid peroxidation process and to enhance the antioxidant enzyme activity.

\section{Conclusions}

The presented research showed many differences among physiological responses of gastrointestinal tract to a diet supplemented with raw or fermented blue or yellow lupin seeds. The inclusion of yellow lupin seeds in the diets of rats had a positive effect on the feed intake and feed utilization in comparison with blue lupin, but blue lupin in the diet had a more beneficial effect on gas- 
trointestinal fermentation processes. Lupin seeds treated with Candida utilis had a better chemical composition than unprocessed seeds, because of a higher protein and amino acid content, low $\mathrm{pH}$ and reduced antinutritional substance content. Fermentation had a positive influence on protein digestibility, body mass gain and protein efficiency ratio of rats, but despite the acidic $\mathrm{pH}$, it did not have a beneficial effect on the gastrointestinal parameters of rats. On the other hand, it had a positive influence on some bacterial enzyme activity and it increased HDL cholesterol concentrations in the blood serum. Taking this into account, lupin seeds fermented with Candida utilis could be recommended as an alternative, protein-rich component of diets for animals and people. However, it should be remembered that lupin is a potential allergen and its status after fermentation has not yet been investigated.

\section{Acknowledgements}

The study was supported by the State Committee for Scientific Research no. 2011/01/B/NY9/00232.

\section{References}

1. Siró I, Kápolna E, Kápolna B, Lugasi A. Functional food. Product development, marketing and consumer acceptance - a review. Appetite. 2008;51:456-67. http://dx.doi.org/10.1016/j.appet.2008.05.060

2. Klewicka E, Zduńczyk Z, Juskiewicz J. Effect of lactobacillus fermented beetroot juice on composition and activity of cecal microflora in rats. Eur Food Res Technol. 2009;229:153-7. http://dx.doi.org/10.1007/s00217-009-1036-x

3. Bedani R, Pauly-Silveira N, Roselino M, de Valdez G, Rossi E. Effect of fermented soy product on the fecal microbiota of rats fed on a beef-based animal diet. J Sci Food Agric. 2010; 90:233-8. http://dx.doi.org/1002/jsfa.3800

4. Bartkiene E, Juodeikiene G, Vidmantiene D, Zduńczyk Z, Zduńczyk P, Juśkiewicz J, et al. Influence of diets to Wistar rats supplemented with soya, flaxseed and lupine products treated by lactofermentation to improve their gut health. Int J Food Sci Nutr. 2013;64:730-9. http://dx.doi.org/3109/09637486.2013.775230

5. Mathew AG, Chattin SE, Robbins CM, Golden DA. Effects of a direct-fed yeast culture on enteric microbial populations, fermentation acids, and performance of weanling pigs. J Anim Sci. 1998;76:2138-45.

6. White LA, Newman MC, Cromwell GL, Lindemann MD. Brewers dried yeast as a source of mannan oligosaccharides for weanling pigs. J Anim Sci. 2002;80:2619-28.

7. Dobrzański Z, Dolińska B, Chojnacka K, Opaliński S, Ryszka F. Using of yeast in animal nutrition. Acta Sci Pol Med Vet. 2006;5:49-66 (in Polish).

8. Shindu SC, Khetarpaul N. Fermentation with one step single and sequential cultures of yeast and lactobacilli: effect on antinutrients and digestibilities (in vitro) of starch and protein in an indigenously developed food mixture. Plant Foods Hum Nutr. 2003;58:1-10. http://dx.doi.org/10.1023/B:QUAL.0000040326.72490.83

9. Khattab RY, Arntfield SD, Nyachoti CM. Nutritional quality of legume seeds as affected by some physical treatments, Part 1: Protein quality evaluation. Food Sci Technol. 2009;42:110712. http://dx.doi.org/10.1016/j.lwt.2009.02.008

10. Hung ATY, Su TM, Liao CW, Lu JJ. Effect of probiotic combination fermented soybean meal on growth performance, lipid metabolism and immunological response of growing-finishing pigs. Asian J Anim Vet Adv. 2008;3:431-6. http://dx.doi.org/10.3923/ajava.2008.431.436

11. Liu X, Feng J, Xu Z, Lu Y, Liu Y. The effects of fermented soybean meal on growth performance and immune characteristics in weaned piglets. Turk J Vet Anim Sci. 2007;31:341-5.

12. Kim JC, Pluske JR, Mullan BP. Lupins as a protein source in pig diets. CAB Rev. 2007;2:003. http://dx.doi.org/10.1079/PAVSNNR20072003

13. Yabaya A, Akinyanju JA, Jatou ED. Yeast enrichment of soybean cake. World J Dairy Food Sci. 2009;4:141-4.

14. Jezierny D, Mosenthin R, Bauer E. The use of grain legumes as a protein source in pig nutrition: A review. Anim Feed Sci Technol. 2010;157:111-28. http://dx.doi.org/10.1016/j.anifeedsci.2010.03.001

15. Zduńczyk Z, Juśkiewicz J, Frejnagel S, Gulewicz K. Influence of alkaloids and oligosaccharides from white lupin seeds on utilization of diets by rats and absorption of nutrients in the small intestine. Anim Feed Sci Technol. 1998;72:143-54. http://dx.doi.org/10.1016/S0377-8401(97)00173-9

16. Seve B, Kerros C, Lebreton Y, Quemener B, Gaborit T, Bouchez P. Effect of the extraction of $\alpha$-galactosides from toasted or raw soybean meal on dietary nitrogen and fat utilization in the young pig. In: Huisman J, van der Poel TFB, Liner JE, editors. Recent advances of research in antinutritional factors in legume seeds. Wageningen, the Netherlands: Pudoc; 1989. pp. 276-9.

17. Sobotka W, Stanek M, Bogusz J, Matusevicius P. The effect of oligosaccharides and alkaloids contained in yellow and blue lupine seeds on feed intake, body weight and fermentation processes in the cecum of rats. Vet Med Zoot. 2013;63:85-95.

18. Łoza A, Lampart-Szczapa E. Allergenicity of lupine proteins - a review. Pol J Food Nutr Sci. 2008;58:283-7.

19. Kasprowicz-Potocka M, Borowczyk P, Gulewicz P, Zaworska A, Frankiewicz A. The optimization of fermentation conditions for narrow lupin seeds using the yeast Saccharomyces cerevisiae towards maximizing the production of protein. Fragm Agron. 2012;29:78-86 (in Polish).

20. AOAC Official Methods of Analysis. Agricultural chemicals. Gaithersburg, MA, USA: Association of Official Analytical Chemists; 2007.

21. Zalewski K, Lahuta LB, Horbowicz M. The effect of soil drought on the composition of carbohydrates in yellow lupin seeds and triticale kernels. Acta Physiol Plant. 2001; 23:73-8. http://dx.doi.org/10.1007/s11738-001-0025-x

22. Chilomer K, Zaleska K, Ciesiołka D, Gulewicz P, Frankiewicz A, Gulewicz K. Changes in the alkaloid, $\alpha$-galactoside and protein fractions content during germination of different lupin species. Acta Soc Bot Pol. 2010;79:11-20. http://dx.doi.org/10.5586/asbp.2010.002

23. Kaczmarek SA, Kasprowicz-Potocka M, Hejdysz M, Mikuła $\mathrm{R}$, Rutkowski A. The nutritional value of narrow-leafed lupin (Lupinus angustifolius) for broilers. J Anim Feed Sci. 2014;23:160-6.

24. Bekatorou A, Parianos C, Koutinas AA. Production of food grade yeasts. Food Technol Biotechnol. 2006;44:407-15.

25. Canibe N, Højberg O, Badsberg JH, Jensen BB. Effect of feeding fermented liquid feed and fermented grain on gastrointestinal ecology and growth performance in piglets. J Anim Sci. 2007;85:2959-71.

http://dx.doi.org/10.2527/jas.2006-744

26. Vidal-Valverde C, Frias J, Prodanov M, Tabera J, Ruiz R, Becon J. Effect of natural fermentation on carbohydrates, riboflavine and trypsin inhibitor activity of lentils. Z Lebensm Untersuch Forsch A. 1993;197:449-52. http://dx.doi.org/10.1007/BF01202616 
27. Khattab RY, Arntfield SD. Nutritional quality of legume seeds as affected by some physical treatments, 2 . Antinutritional factors. Food Sci Technol. 2009;42:1113-8. http://dx.doi.org/10.1016/j.lwt.2009.02.004

28. Egounlety M, Aworth OC. Effect of soaking, dehulling, cooking and fermentation with Rhizopus oligosporus on the oligosaccharides, trypsin inhibitor, phytic acid and tannins of soybean (Glycine max Merr.), cowpea (Vigna unguiculata L. Walp) and groundbean (Macrotyloma geocarpa Harms). J Food Eng. 2003;56:249-54. http://dx.doi.org/10.1016/S0260-8774(02)00262-5

29. Trojanowska K, Markiewicz M, Czaczyk K, Mueller A, Gulewicz K. Lupin extract as a raw material used in microbial feed protein biosynthesis. Biotechnologia. 1991;3-4:131-6 (in Polish)

30. Chu GM, Ohmori H, Kawashima T, Funaba M, Matsui T. Brewer's yeast efficiently degrades phytate phosphorus in a corn-soybean meal diet during soaking treatment. Anim Sci J. 2009;80:433-7. http://dx.doi.org/10.1111/j.1740-0929.2009.00651.x

31. Mbata TI, Ikenebomeh MJ, Alaneme JC. Studies on the microbiological, nutrient composition and antinutritional contents of fermented maize flour fortified with bambara groundnut (Vigna subterranean L). Afr J Food Sci. 2009;3:165-71.

32. Wakil SM, Onilude AA. Microbiological and chemical changes during production of malted and fermented cereallegume weaning foods. Adv Food Sci. 2009;31:139-45.

33. Ferreira IM, Pinho O, Vieira E, Tavarela JG. Brewers Saccharomyces yeast biomass: characteristics and potential applications. Trends Food Sci Technol. 2010;21:72-84. http://dx.doi.org/10.1016/j.tifs.2009.10.008

34. Stanek M, Bogusz J. The effect of yellow lupin (Lupinus luteus L.) seeds on fermentation processes in the cecum of rats. Zesz Problem Post Nauk Rol. 2007;522: 413-8 (in Polish).

35. Juśkiewicz J, Godynicka-Kłos I, Matusevicius P, Zduńczyk Z, Juśkiewicz M. Influence of pea and lupin oligosaccharides on caecal short-chain fatty acids production and nitrogen excretion patterns in rats. Pol J Food Nutr Sci. 2006;15/56:77-82.

36. Gulewicz K, Wardeńska M. Biological activity of raffinose family oligosaccharides isolated from the leguminous seed. Zesz Problem Post Nauk Rol. 2003;495:349-57 (in Polish).

37. Champ M, Berot S, Kozlowski F, Lecannu G, Delort-Laval J. Volatile fatty acid production from lupin meal in the cecum of the rat: the role of cell wall polysaccharides and $\alpha$-galactosides. Anim Feed Sci Technol. 1991;32:177-83. http://dx.doi.org/10.1016/0377-8401(91)90020-S

38. Martins JM, Riottot M, de Abreu MC, Viegas-Crespo AM, Lança MJ, Almeida JA, et al. Cholesterol-lowering effects of dietary blue lupin (Lupinus angustifolius L.) in intact and ileorectal anastomosed pigs. J Lipid Res. 2005;45:1539-47.

39. Chango A, Villaume C, Bau H, Schwertz N, Nicolas JP, Mejean L. Effects of casein, sweet white lupin and sweet yellow lupin diet on cholesterol metabolism. J Sci Food Agric. 1998;76:303-9. http://dx.doi.org/10.1002/(SICI)1097-0010(199802)76:2

40. Rahman MH, Hossain A, Siddiqua A, Hossain I. Hematobiochemical parameters in rats fed Lupinus angustifolius (sweet lupin) seed protein and fiber fractions. J Clin Biochem Nutr. 1996;20:99-111. http://dx.doi.org/10.3164/jcbn.20.99

41. Spielmann J, Shukla A, Brandsch C, Hirche F, Stangl GI, Eder K. Dietary lupin protein lowers triglyceride concentrations in liver and plasma in rats by reducing hepatic gene expression of sterol regulatory element-binding protein-1c. Ann Nutr Metab. 2007;51:387-92. http://dx.doi.org/10.1159/000107720

42. Osman M, Mahmoud GI, Romeilah RM, Fayed SA. Lupin seeds lower plasma lipid concentrations and normalize antioxidant parameters in rats. Grasas Aceites. 2011;62:162-70. http://dx.doi.org/10.3989/gya.056310 